\title{
Research on Information Models for the Construction Schedule Management Based on the IFC Standard
}

\author{
Weirui Xue, Yaowu Wang, Qingpeng Man \\ School of Management, Harbin Institute of Technology (China) \\ xueweirui@,outlook.com,ywwangbit@,vip.163.com,manqp@126.com
}

Received: October 2014

Accepted: April 2015

\section{Abstract:}

Purpose: The purpose of this article is to study the description and extension of the Industry Foundation Classes (IFC) standard in the construction schedule management, which achieves the information exchange and sharing among the different information systems and stakeholders, and facilitates the collaborative construction in construction projects.

Design/methodology/approach: The schedule information processing and coordination are difficult in complex construction projects. However, Building Information Modeling (BIM) provides a platform for exchanging and sharing information among information systems and stakeholders based on the IFC standard.

Through analyzing the plan, implementing, check and control, the information flow in the schedule management is reflected based on the IDEF0. According to the IFC4, the information models for the schedule management are established, which not only includes the each aspect of the schedule management, but also includes the cost management, the resource management, the quality management, the risk management and so on.

Findings: The information requirement for the construction schedule management can be summarized into three aspects: the schedule plan information, the implementing information and the check and control information, and three aspects can be described through the existing 
and extended entities of the IFC4, and different information models are established respectively.

Originality/value: The main contribution of the article is to establish construction schedule management information models, which achieve the information exchange and sharing in the construction project, and facilitate the development of the application software to meet requirements of the construction project.

Keywords: construction schedule management, collaborative construction, BIM, IFC standard, information model

\section{Introduction}

As an important management target, the schedule management has been a research hotspot in the AEC (Architecture, Engineering and Construction) industry in the past 50 years (Lorterapong \& Ussavadilokrit, 2012). The implementation of the schedule management not only improves the effective use of various resources in the construction project, but also achieves an optimization through coordinating the cost management, the quality management, the risk management and so on. With the more complexity, huger of construction projects, the schedule management target often is out of control (He, Luo \& Ren, 2012). On the other hand, the information processing and coordination among information systems and stakeholders are difficult in complex construction projects.

The construction is a process of the collaborative construction (Nikas, Poulymenakou \& Kriaris, 2007; Soibelman, Sacks, Akinc, Dikmen, Birgonul \& Eybpoosh, 2010), which needs the multidisciplines' cooperation, and more attentions have been attracted by the collaborative construction, for example, the collaboration knowledge management (Dave \& Koskela, 2009; El-Diraby, Lima \& Feis, 2005), the collaborative working supported by IT (Hammad, Wang \& Mudur, 2009; Isikdag \& Underwood, 2010) and so on. With the development and application of IT in the AEC industry, it provides a collaborative environment (Erdogan, Anumba, Bouchlaghem \& Nielsen, 2008). Especially Building Information Modeling (BIM), it provides the platform for the collaboration among the multi-disciplines and multi-stakeholders through exchanging and sharing the data (Singh, Gu \& Wang, 2011).

As the sharing platform, BIM has been used in the construction schedule management to track the construction information, to avoid the schedule delays caused by component conflict, and to management the schedule information, so BIM provides an innovative way for the information management in the construction project. In order to increasing the adoption of BIM, the Industry Foundation Classes (IFC), the one of major enablers is a research hotspot in the AEC industry (Tse, Wong \& Wong, 2005). 
This paper studies the description and extension of the IFC standard in the construction schedule. Based on the theory of the construction project management, the information flow model is established to describe the each stage of construction schedule, and the IFC entities including the existing and extended are established relationships to describe the process in different stages. Through establishing the IFC standard of construction schedule, the dynamic and complex process of the construction schedule can be analyzed collaboratively, and BIM-based application software can be developed.

\section{Literature Review}

The IFC standard is developed by buildingSMART, which is an international organization for openBIM, and their mission is "to enable interoperability among industry processes of all different professional domains in civil engineering projects by allowing the computer applications used by all project participants to share and exchange project information". The first vision of the IFC standard was released in 1997, and the new vision is the IFC4 released in March, 2013. In the IFC standard, there are 4 layers (Resource layer, Core layer, Interoperability layer and Domain layer), and lots of types, entities, rules and functions are defined in EXPRESS data specification language to describe the actors, process, control, resource, product and so on (BuildingSMART, 2014).

As the standard of BIM, lots of researchers paid attention to the IFC standard. Fu, Aouad, Lee, Mashall-Ponting and Wu (2006) developed an IFC viewer, which was defined as the holistic interface of the $\mathrm{nD}$ modelling tool to integrate the decision-making information. Based on BIM, Vanlande, Nicolle and Cruz (2008) researched the information management in the full lifecycle of the AEC industry, and used IFC files to facilitate the sharing process. Based on the IFC standard, Nepal, Zhang, Webster, Staub-French, Pottinger and Lawrence (2009) researched the expression of the geometry and topology of the components in BIM. Man and Sun researched the structure and expression of the construction information based on the IFC standard (Man \& Sun, 2011). Taking the cost estimation for tendering of building projects as the example, Ma, Wei and Zhang (2013) discussed the key issues for semi-automatic and specification-compliant cost estimation based on the IFC standard. Göekce, Göekce and Katranuschkov (2013) presented a new product catalog structure based on the IFC standard, which could achieve the integration of the product and cost information.

As one of the most important targets for a construction project, the schedule management was studied based on the IFC standard. Froese and Yu developed the models which were the project-management-related portions (including the estimates and schedule) of IFC, and the various modelling issues were discussed, for example, costs, construction processes, resources, products, and project documents for work plans and cost estimates (Froese \& Yu, 1999). Faraj, Alshawi, Aouad, Child and Underwood (2000) developed the WISPER (Web-based 
IFC Shared Project EnviRonment), which provided a collaborative working environment for construction. Based on IFC and the web, the main project database was developed, which could be used by the construction applications, such as the design, visualization, estimating, planning, specifications and so on. Tanyer and Aouad developed a web-based 4D planning tool, which was a part of an IFC-based single project database (Tanyer \& Aouad, 2005). When completing the graphical user interface (GUI) of building elements, the users could create the construction planning, and building elements could link with the time information to see the 4D simulation. Based on IFC, Ma, Wei, Song and Lou (2011) established the information model for construction cost estimating for tendering in China. There were seven parts included in the information requirement model, and each part was established the IFC-based information model. In the schedule information model, the objects, the relationships, and the attributes of the IFC $2 \times 3$ final were used to describe the project schedule. Zhang, Yu, Li and $\mathrm{Hu}$ (2014) presented the IFC-GIM for Virtual Construction (VC). Based on the model, a 4D construction analysis and management system was developed, and descriptions and relationships of the quantity, the schedule, the resource consumption, and the cost based IFC were studied to achieve the data exchange in the system.

In these cases, the data based on IFC were exchanged and shared commendably, which promoted the applications for the various construction management systems. However, the IFC entities are not sufficient to support the use cases, and the further development is required for the more use cases in the AEC/FM industry (Weise, Liebich \& Wix, 2009). Such as the schedule management, the information model was based on the existing objects, relationships, and attributes of the IFC standard. But the schedule is a dynamic and complex process, which requires the more detailed information model.

\section{Methodology}

The new version of the IFC standard is the IFC4. Comparing the IFC $2 \times 3$ final version, the IFC4 covers eight domains: building controls, plumbing fire protection, structural elements, structure analysis, HVAC, electrical, architecture and construction management. In the construction management, the major improvements of the IFC4 include rework of the scheduling definitions, adding calendar support, simplification of task relations, rework for cost items and construction resources which linked to the schedule and BIM. In this paper, the study of the IFC entities for the construction schedule will base on the IFC4.

In the IFC4, there are 1609 entities which include objects, attributes and relationships, and relationship entities are 48 , and property sets are 408 . Through the relationship entity, the object entity can associate with another object(s) or attribute(s). As researched in other papers, the EXPRESS-G is used to express information models. On the other hand, the IFC 
standard is not sufficient for the schedule management, so it is necessary to extend the IFC standard to meet the requirement for the paper.

It is three mechanisms that are used to extend the IFC standard, IfCProxy, extending new entities and property sets (or types) (Weise et al., 2009). About the IfcProxy, the undefined entity can be expressed by the IfcProxy. The entity IfcProxy can be expressed by using an instance, and the defined entity can be described by using the ProxyType and the Tag attribute. About extending new entities, it is the feasible way to upgrade the version of the IFC standard from the IFC1 to IFC4. The new entities which be extended should be contact with existing entities, for example, the derivative relationship, the associated relationship. About extending the property sets or types, new attributes can be extended to describe the information. Extending new entities and property sets (or types) are appropriate mechanisms to improve the IFC standard, so they will be used in this paper.

\section{Information Requirements of the Schedule Management}

The schedule management is one of the "three most important goals" for the construction project management. It presents construction activities of the construction site in the spacetime. The quality of the construction schedule is directly related to the benefit of construction enterprises, the duration, the cost and the quality of the project, and the expected benefits, costs, plans can be reflected through the construction schedule.

The construction duration is the object of the schedule management. In the schedule management, the following works can be involved: (1) according to the target duration, different plans are made; (2) implementing plans, and monitoring the actual schedule in the construction process continuously; (3) analyzing reasons of the schedule variance; (4) controlling the construction process through making the appropriate adjustments and modifications. Through controlling the factors, coordinating the relationships, and implementing a variety of possible ways, the actual duration can be followed with plans. On the other hand, shortening the construction duration which is associated with the cost management, the quality management, and the risk management is the other goal for the schedule management.

\subsection{Making the Schedule Plan}

Under the total duration and construction conditions, the reasonable construction durations of different stages and construction procedures should be determined to coordinate all construction aspects in space-time. The schedule management includes different plans, for 
instance, the general plan, the unit project plan and so on. In the plans, maximizing the rational use of funds, labors, equipment and supplies should be considered.

\subsection{Implementing the Schedule Plan}

According to the plan, the appropriate construction technologies are chose. The flow construction is the sound technology, and the construction process is divided into different construction sections and construction layers to connect the different construction procedures, which reduces the obstructions in the construction process, and improves the productivity. At the same time, the actual influences of the cost management, the quality management, the risk management are considered.

\subsection{Examining the Schedule Plan}

In the examining stage, the following works have to be done: (1) collecting the data of the construction process; (2) analyzing the deviation (comparing the actual schedule to the schedule plan); (3) analyzing the trend of the construction schedule and forecasting the subsequent construction schedule. Examining the schedule plan and forecasting the schedule provide the reliable basis for the subsequent schedule adjustment, and improve the sensitivity and accuracy of the schedule control.

\subsection{Controlling the Construction Schedule}

Because of the influencing factors in the construction schedule, the deviation is reasonable, and the control is more important. In the control stage, the following works have to be done: (1) analyzing the reasons of the deviation; (2) adjusting the schedule dynamically; optimizing the adjustment. Deviation analysis, dynamic adjustment and optimization are the most difficult and the most critical parts in the schedule management.

In order to reveal the relationships between making the schedule plan, implementing the schedule plan, examining the schedule plan and controlling the construction schedule from the system perspective, the IDEFO is used to describe the relationship of the input and output information among the modules, and realize the information requirements between the modules, as showed in the Figure 1. 


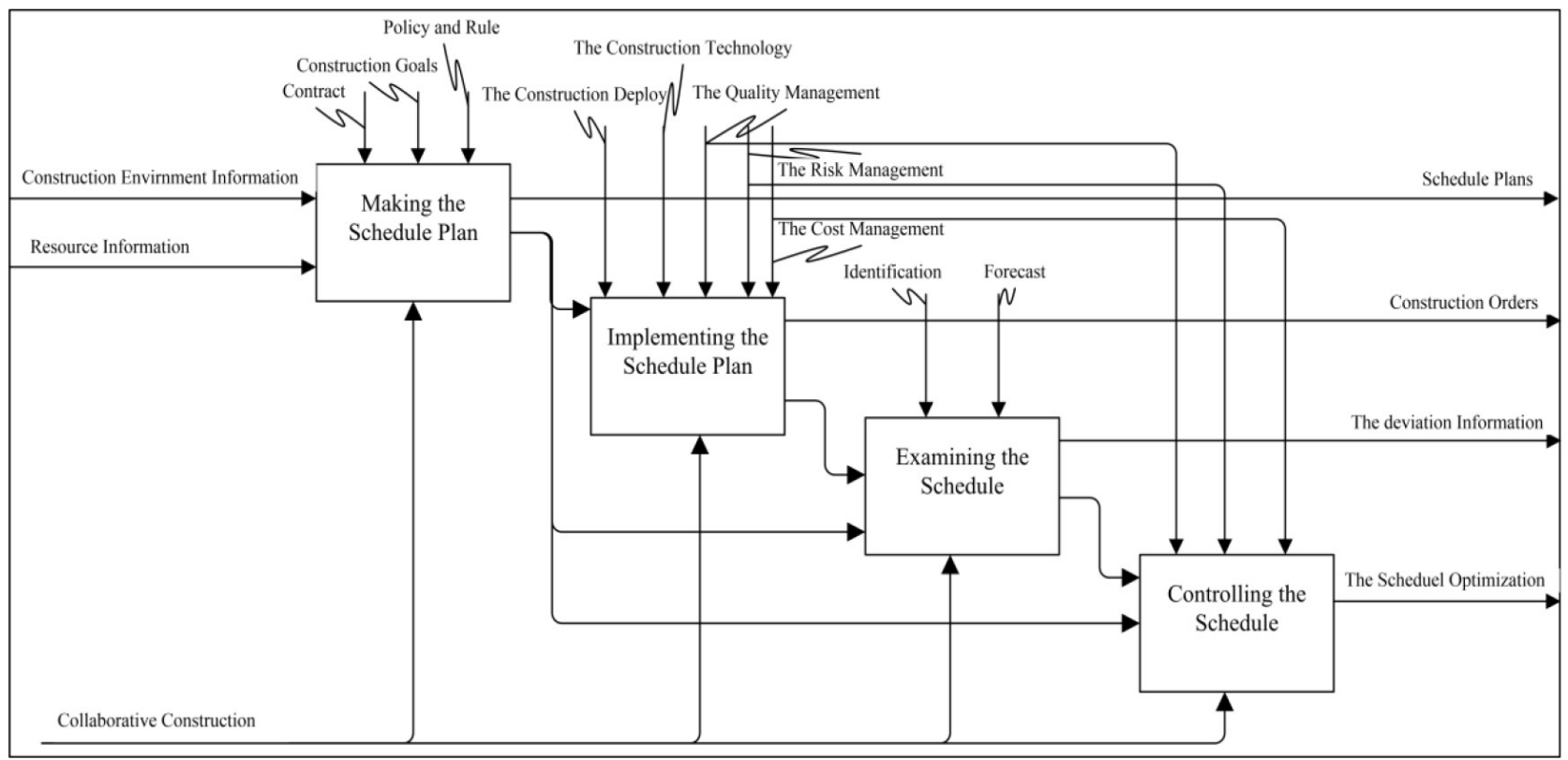

Figure 1 . The information flow of the schedule management by IDEF0

\section{Expression of the Schedule Management Information by Using the IFC Standard}

\subsection{The Schedule Plan}

A construction project can be expressed by the entity IfcProject (an abstract entity). In the plan stage, the entity IfcProject includes different kinds of plans which can be described by the entity IfCWorkPlan, and the entity IfCRelDeclares can be used to describe the relationship between the construction project and the schedule plan. The relationship IfCRelDeclares is used to handle the declaration of the objects or properties to a project in the IFC4. The new entity IfcConstructionGeneralSchedule- Plan is the subtype of IfcWorkPlan, which expresses the general plan of the construction project. The general plan can be decomposed to many unit project plans, which are described by the new entity IfcUnitProjectSchedulePlan. In the unit project, there are many construction sections, which are constructed in sequence, and the construction project can be finished step by step. The new entity IfcConstructionSection is used to describe the construction section, and it can establish relationship with the entity IfcUnitProjectSchedulePlan by the entity IfcRelNests. On the other hand, some entities also can expresse the decomposition applied to the non-physical object. In the IFC standard, the entity IfcTask expresses an identifiable unit of work to be carried out in a construction project. In this paper, the entity IfcTask expresses the explicit work in the plan(s). The entity IfcRelSequence describes the sequence of these tasks, for example start to start, start to finish, finish to finish or finish to start. The entity IfcWorkSchedule expresses the control of these tasks, which establishes the relationship with IfcTask by the entity IfCRelAssignsToControl. Figure 2 shows the schedule plan information model. 


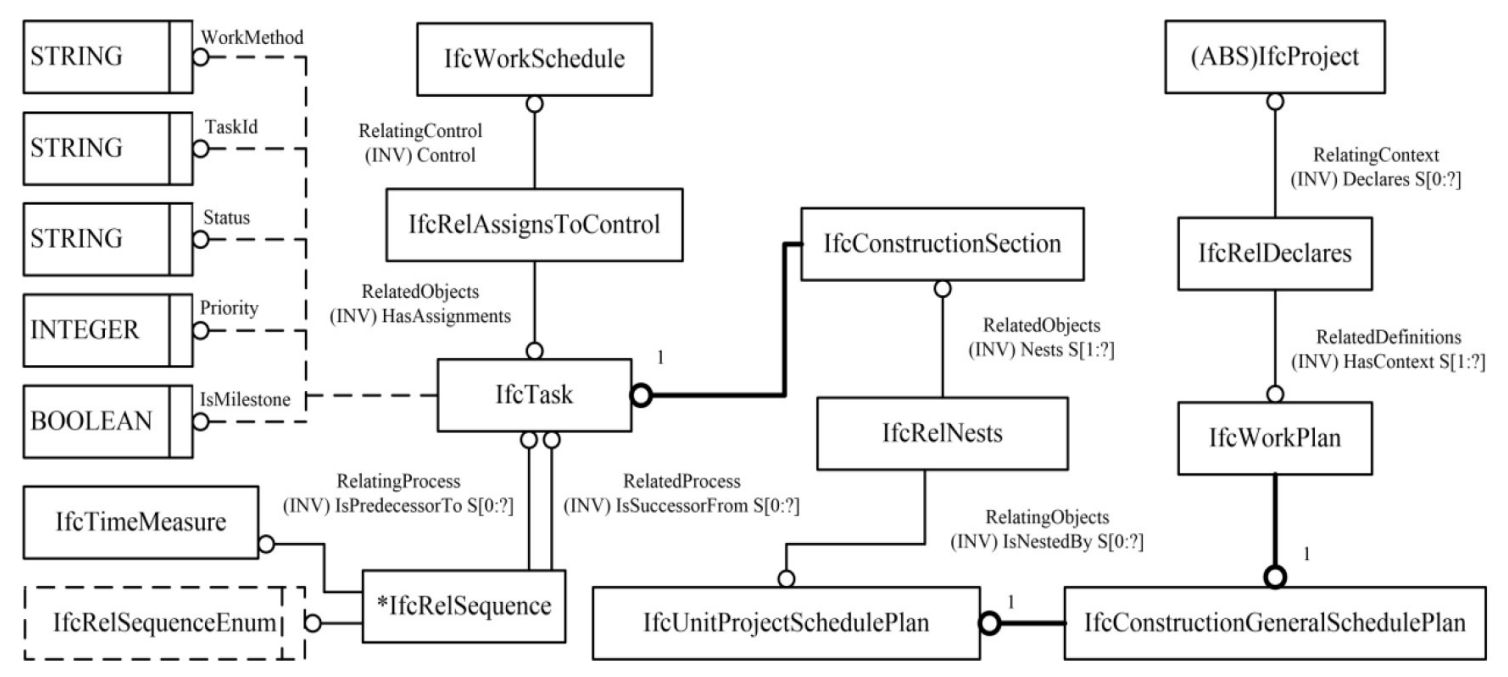

Figure 2. The schedule plan information model

\subsection{The Schedule Implementing}

The abstract entity IfcProcess expresses the construction process. In the process, the schedule is affected by the cost, the quality, the resource, the product, the risk and so on. The new entity IfcConstruction is used to describe the implementing of the construction schedule plan, the entity IfcCostItem is used to describe the cost which happened in the construction process. The new abstract entity IfcQualityManagement describes the quality management in the construction process, the new abstract entity IfcRiskManagement describes the risk management in the construction process, and the entity IfCResource is used to describe the resource which used in the construction process. The entity IfcProduct is used to describe the in-put products and the out-put products in the construction process.

The entities of IfcConstruction, IfcCostItem, IfcQualityManagement, IfcRiskManagement and IfCResource can be established the relationship with IfCProcess by the relationship entity IfCRelAssignsToProcess. The in-put products can be contacted with IfCProcess by the entity IfCRelAssignsToProcess, and the out-put products can be contacted with IfCProcess by the entity IfCRelAssignsToProduct. Figure 3 shows the schedule implementing information model. 


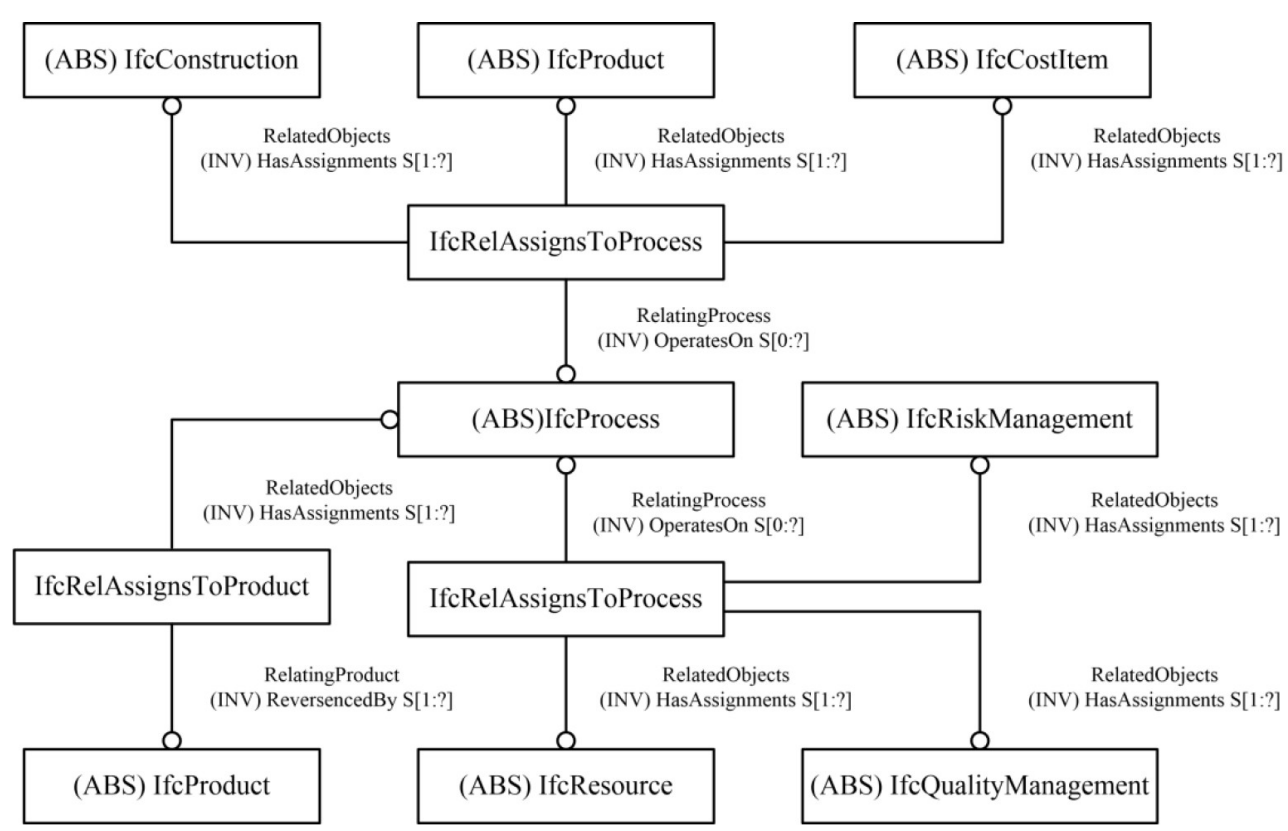

Figure 3. The schedule implementing information model

\subsubsection{Expression of the Implementing of the Construction Information}

There are three construction organization forms in the construction process: the sequential construction, the flow construction, and the parallel construction. Because of the advantages of the flow construction, it will be researched in this paper. The new entities IfcSequentialConstruction, IfcFlowConstruction and IfcParalellConstruction are the subtypes of the IfcConstruction, which showed in the Figure 4.

Given the different organization forms, the flow construction includes the rhythmed and specialized flow production, and non-rhythmed and specialized flow production. IfCRhythmedAndSpecializedFlowProduction is used to describe the construction which has the equal rhythm in the construction section, and it is the ideal way to construct. The new entity IfcNonRhythmedAndSpecializedFlowProduction describes the construction which has the unequal rhythm in the construction section, and it is the common way in the construction process. In the transverse section, the flow construction can be decomposed to many construction sections, and the flow construction can be decomposed to many layers in the vertical section, which is described by the new entity IfcConstructionLayer. In order to establish the relationship between the IfcFlowConstruction IfcConstructionSection, and IfcConstructionLayer, the relationship entity IfCRelAssignstoFlowConstruction is used in the flow construction information model, which describes assignment of the objects to a flow construction. Different construction sections and layers have the different construction teams, and the new entity IfcConstructionTeam is used to describe the professional team in the flow construction, and it can establish the relationship with IfcFlowConstruction by the entity 
IfCAssignsToActor. The construction section can be decomposed to different construction types which are described by the new entity IfcConstructiontype.

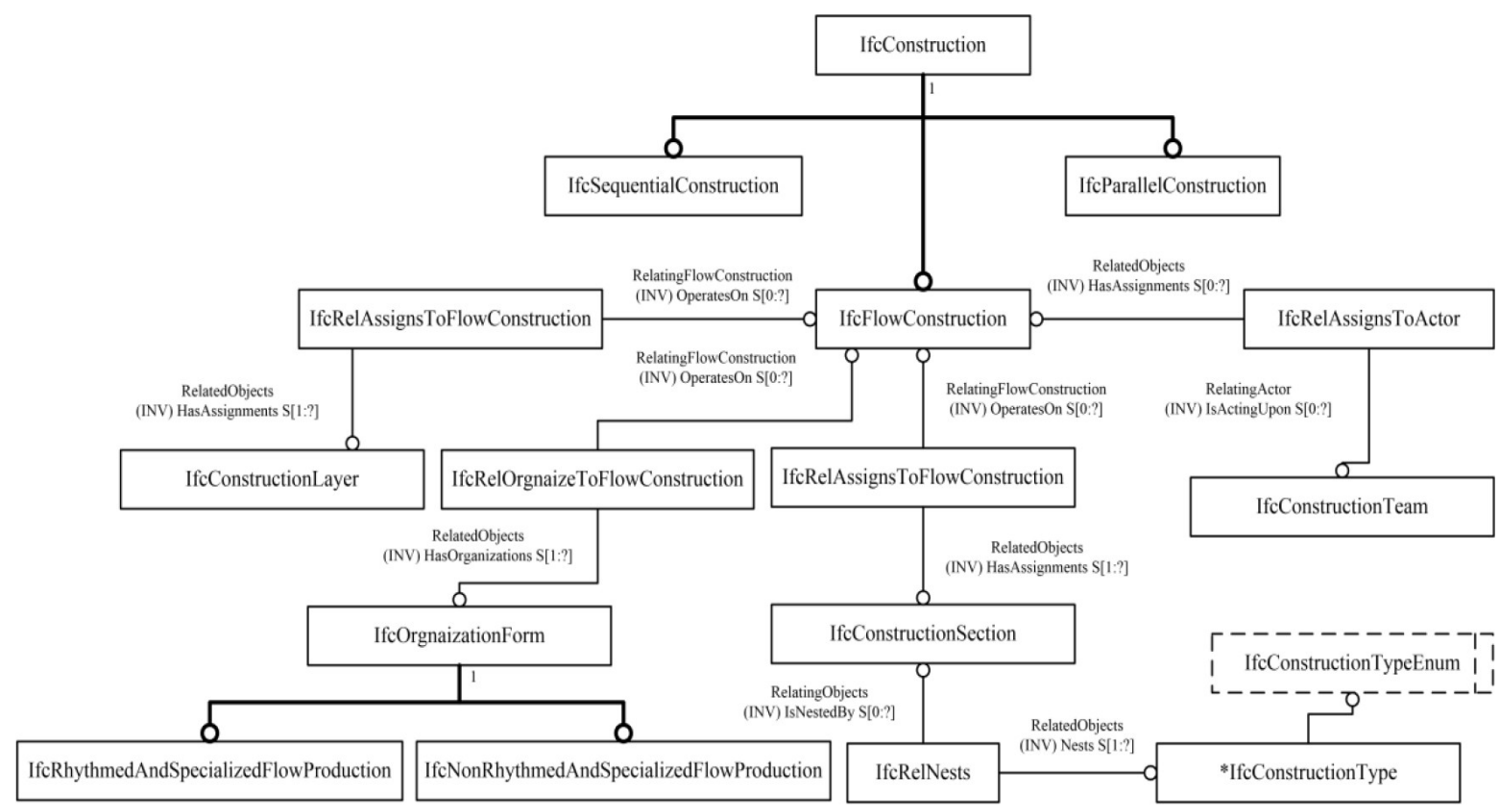

Figure 4. The implementing of the construction information model

\subsubsection{Expression of the Resource Information}

According to the IFC4, the entity IfCResource is used to describe the resource which be used in the project. IfcConstructionResource is used to describe the resources used in the construction process. The entities IfcConstructionEquipmentResource, IfcConstructionMaterialResource, IfcConstructionProductResource, IfcLaborResource, IfcSubContractEquipmentResource and IfcCrewResource describe different resources used in the construction process. Figure 5 shows the resource information model.

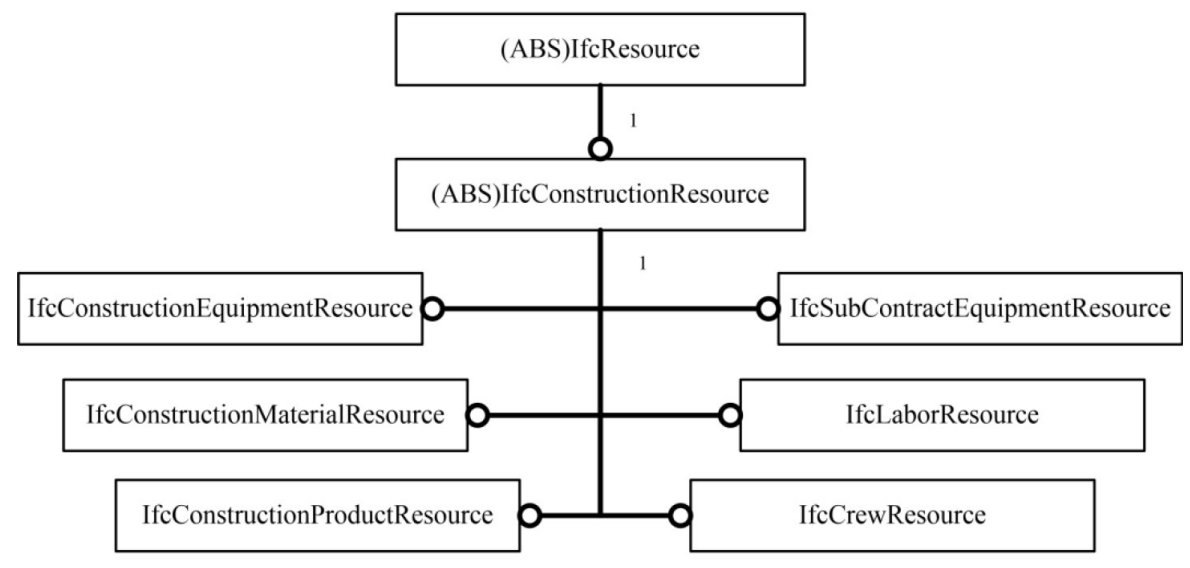

Figure 5. The resource information model 


\subsubsection{Expression of the Cost Information}

The abstract entity IfcCostItem describes the cost happened in the construction process, which include two subtypes, IfcRealCost and IfcCostPlan. The new entity IfcRealCost describes the real cost happened in the construction process, and the new entity IfcCostPlan is used to describe a cost plan which can be made before the construction. The entity IfcCostSchedule is used to describe the cost schedule in the construction process, and it can be established the relationship with IfcCostItem by IfCRelAssignsToControl. As showed in the Figure 6.

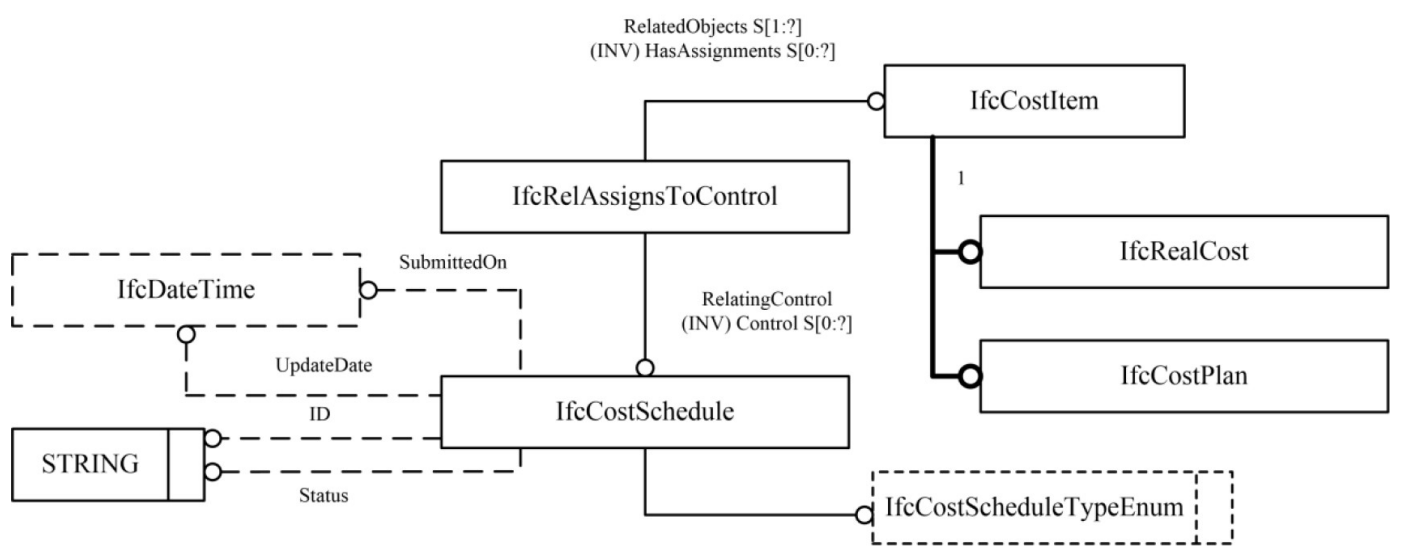

Figure 6. The cost information model

\subsubsection{Expression of the Risk Management Information}

The abstract entity IfCRiskManagement describes the risk management in the construction process. The new entity IfcRiskIdentification is used to describe the identification of the risk in the construction process. The new entity IfcRiskControl is used to describe the risk control in the construction. IfcRiskIdentification and IfcRiskControl can establish the relationship by the entity IfCRelAssignsToControl. Figure 7 shows the risk management information model.

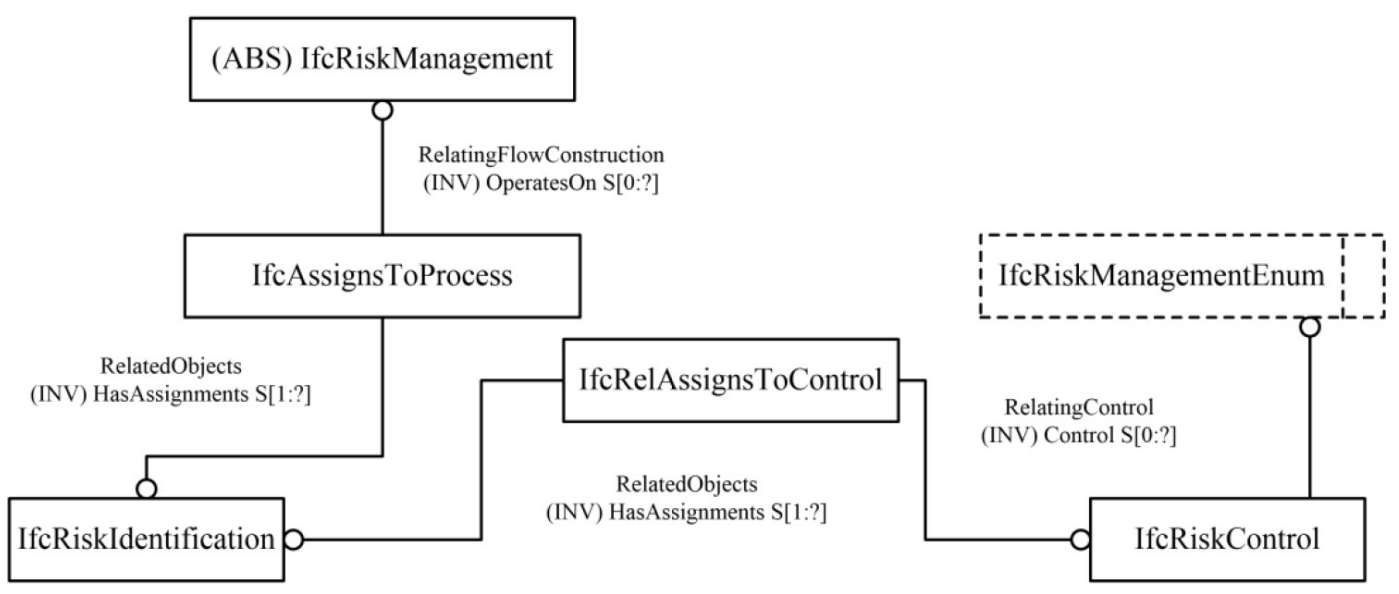

Figure 7. The risk management information model 


\subsubsection{Expression of the Quality Management Information}

The abstract entity IfcQualityManagement is used to describe the quality management in the construction process. The new entity IfcQualityPrecontrol is used to describe the quality control before the construction, for example, the pre-control for the labors, equipment, materials, the choice for the control points and so on. The new entity IfCProcedureQuality describes the control for the quality of operating procedures. The new entity IfcQualityInspection describes the quality test for the unit project, and lots of methods are used to test the product quality. Through setting the properties, the attributes are extended to describe the quality management information. IfcQualityPrecontrol, IfcProcedureQuality and IfcQualityInspection can be established relationship with IfcQualityManagement by IfCAssignsToControl. Figure 8 shows the quality management information model.

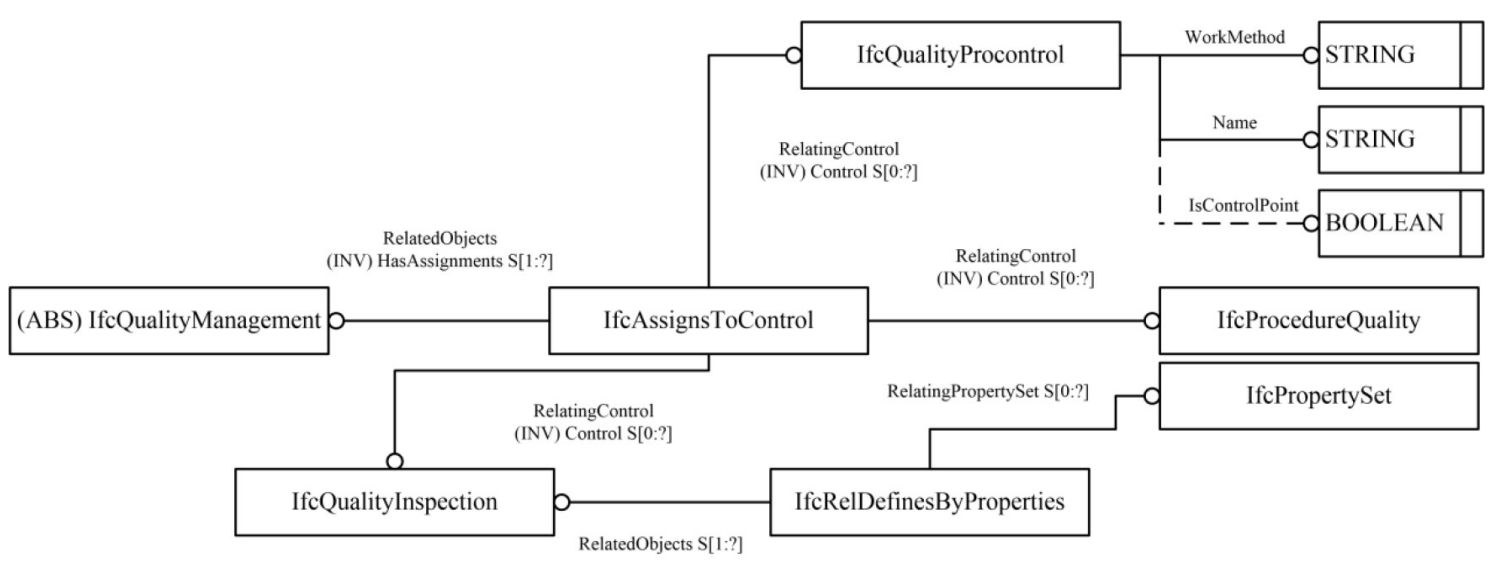

Figure 8. The quality management information model 


\subsection{The Schedule Examination and Control}

The new entity IfcScheduelReport is used to describe the actual schedule of the construction process. In the IfcScheduelReport, the actual conditions of the cost, the resource, the quality management and the risk management are included in the schedule report. The new entity IfcScheduelDeviation describes the analysis for the schedule deviation, which compares the schedule plan to the actual schedule and provides the basis for the schedule control. The new entity IfCRelAssignsToProject is used to handle the assignment of objects (subtypes of IfcObject) of a project. The entity IfcWorkPlan and the entity IfcScheduelDeviation can establish the relationship by the entity IfCRelAssignsToProject, and the entity IfcScheduelReport can establish relationship with IfCScheduelDeviation by the entity IfCRelAssignsToProcess. Figure 9 shows the examination and control information model.

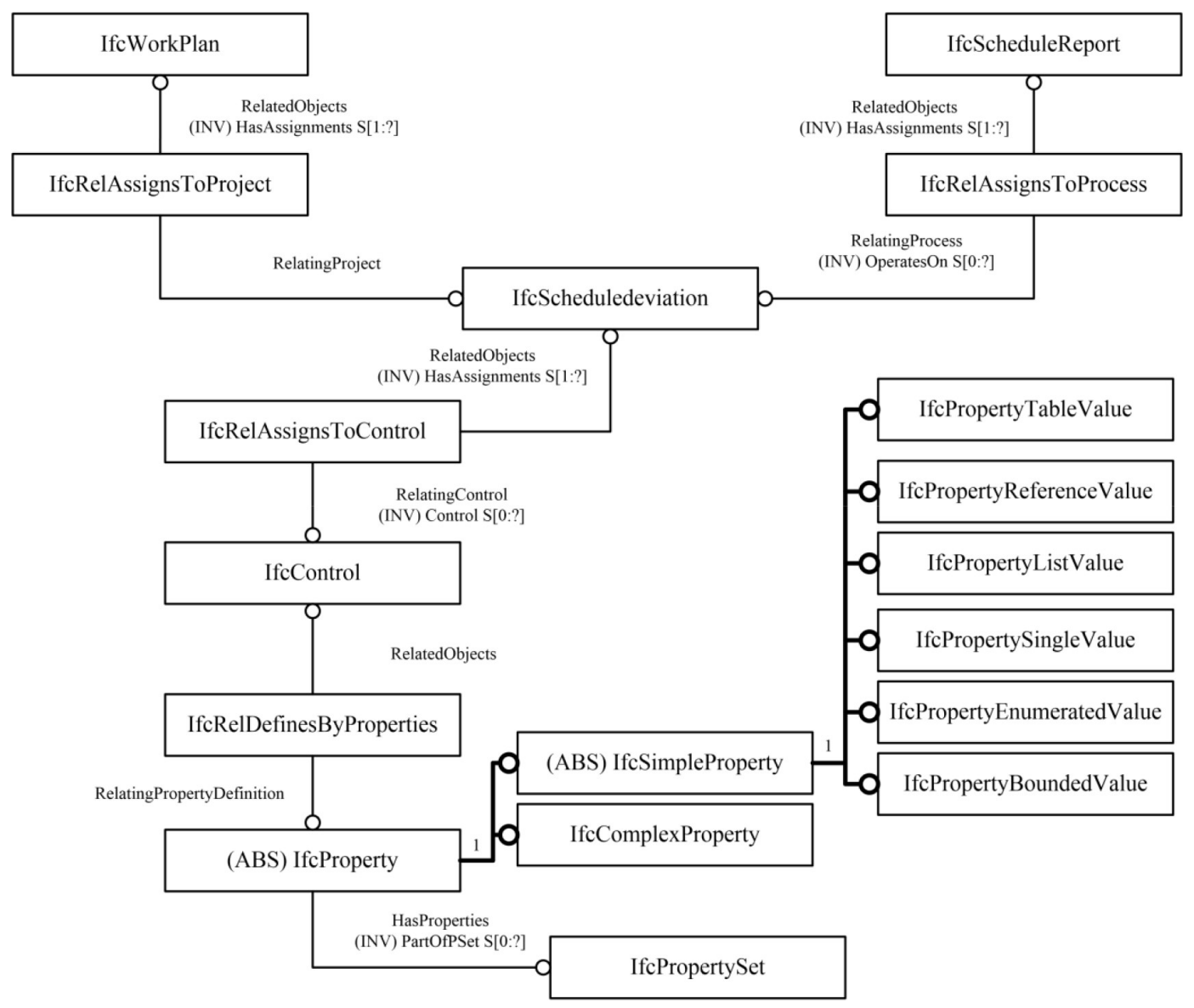

Figure 9. The examination and control information model

On the other hand, the abstract entity IfcControl is used to describe the control of the construction schedule. Because of complex features of the control, IfcProperty is used to describe the properties for the control. IfcPropertySet describes the dynamical extensible properties which can be used in the construction. Based on the requirements of the 
information model, 25 property sets are established in the paper, as showed in the Appendix A. IfcComplexproperty is used to define complex properties in the construction process, which can be reused in different property set.

IfcSimpleProperty is used to describe a single property object, and the subtypes of IfcSimpleProperty (IfcPropertyBoundedValue, IfcPropertyEnumeratedValue, IfcPropertyListValue, IfcPropertyReferenceValue, IfcPropertySingleValue, IfcPropertyTableValue) can be set the property value.

\subsection{The Integrated Schedule Management Information Model}

As showed in the Figure 10, the integrated schedule management information model is established.

In the model, the cost, the resource, the construction process, the quality management and the risk management have the many to one relationship with the process. Through the relationship entity IfCRelAssignsToProcess, the IfcProject and the IfCProcess can establish the relationship, which describes the guidance of the schedule plan to the construction process. Based on the schedule deviation, the construction schedule can be controlled in the right way, which considered the cost, the resource, the quality management and the risk management collaboratively. The IfCProcess and the IfcControl can establish the relationship by the entity IfCAssignsToControl. Because of the dynamic nature, the construction process can extend the properties to meet the information requirements through the IfcDefinesByProperties.

Based on the information model of the schedule management, the application software can be developed in the next step. 


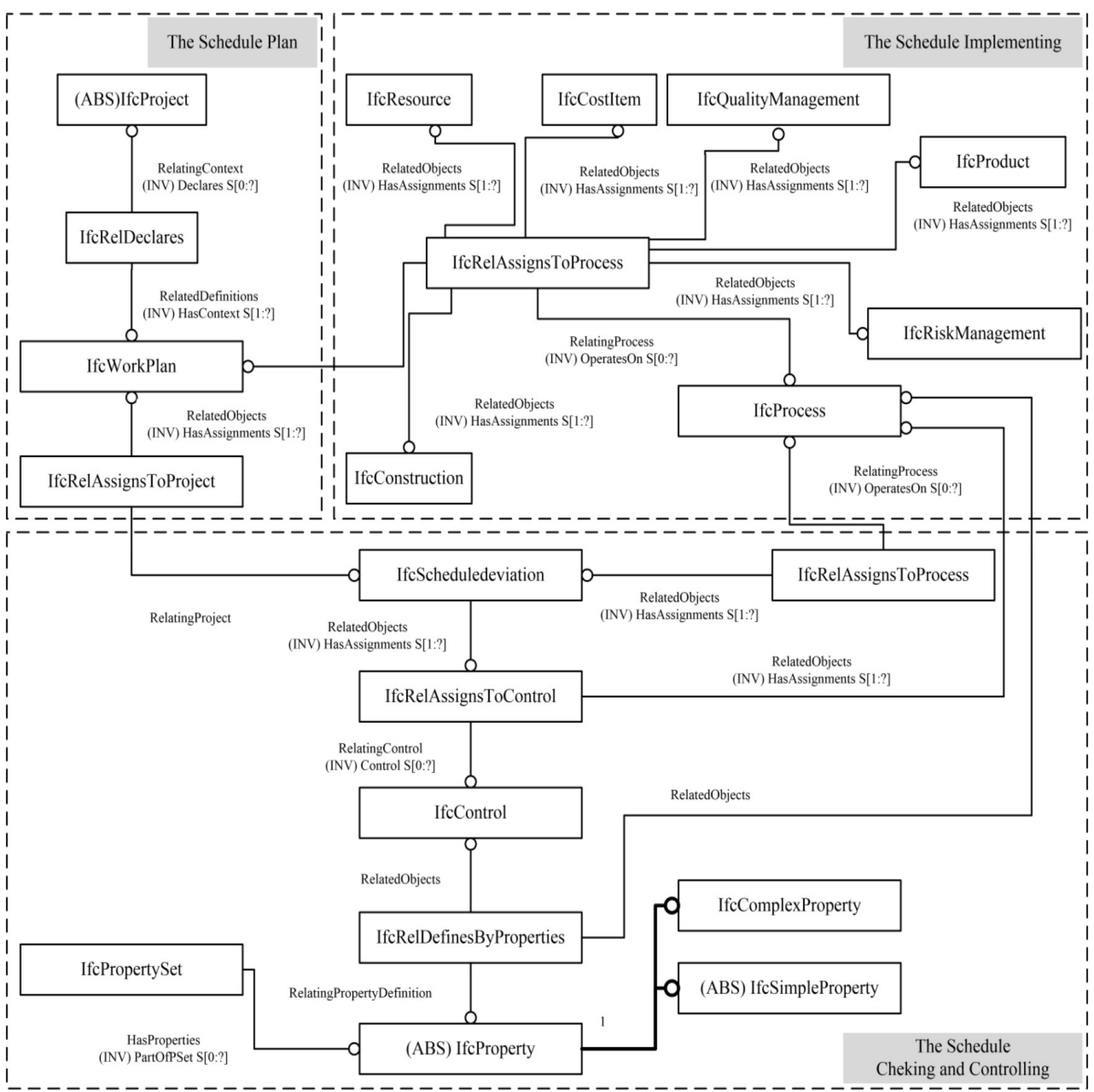

Figure 10. The integrated schedule management information model

\section{Case Study}

A project is a high-rise building with 103 floors and 4 floors basement. Due to the limited length of the paper, Basement $A$ is taken as an example to be described, which provides the application case for the subsequent system development. As a construction section, there are lots of tasks should be done, for example, the support engineering, the earth excavation, the anchor cable construction and the basement construction (showed in the Table 1). The schedule is related with the cost, the resource, the quality management and the risk management in the construction process of Basement $A$, and the information of the cost, the 
resource, the quality management and the risk management are showed in the Table 2 . According to the information of Basement $A$ and the information model described in the paper, the schedule management information model of Basement A can be established (as showed in the Figure 11). An information system can be developed based on the IFC standard to fulfill the information sharing and processing of Basement $A$.

\begin{tabular}{|l|l|l|}
\hline No. & Entity & Name of the task \\
\hline 1 & IfcTask1 & Support Engineering \\
\hline 2 & IfcTask2 & Earth Excavation \\
\hline 3 & IfcTask3 & Anchor Cable Construction \\
\hline 4 & IfcTask4 & Basement Construction \\
\hline
\end{tabular}

Table 1. The task list of Basement A

\begin{tabular}{|c|c|}
\hline Entity & Name \\
\hline IfcLaberResource 1 & Reinforcing Steel Worker \\
\hline IfcLaberResource2 & Concreter \\
\hline IfcLaberResource 3 & Tower Crane Driver \\
\hline IfcConstructionMaterialResource 1 & Reinforcing Steel I \\
\hline IfcConstructionMaterialResource 2 & Reinforcing Steel II \\
\hline IfcConstructionMaterialResource 3 & Reinforcing Steel III \\
\hline IfcConstructionMaterialResource 4 & Concrete \\
\hline IfcConstructionEquipmentResource 1 & Tower Crane \\
\hline IfcConstructionEquipmentResource2 & Concrete Pump \\
\hline IfcConstructionEquipmentResource 3 & Truck \\
\hline IfcConstructionEquipmentResource 4 & Scaffold \\
\hline IfcCostItem 1 & Transport Charges of the Reinforcing Steel \\
\hline IfcCostItem2 & Transport Charges of the Concrete \\
\hline IfcCostItem3 & Labor costs \\
\hline IfcCostItem4 & Material costs \\
\hline IfcCostItem5 & Equipment costs \\
\hline IfcQualityManagement1 & The quality of the Reinforcing Steel Processing \\
\hline IfcQualityManagement2 & The Installation of the Reinforcing Steel \\
\hline IfcQualityManagement3 & Concrete Pouring \\
\hline IfcRiskManagement1 & Guard Rail \\
\hline IfcRiskManagement2 & Safety Net \\
\hline
\end{tabular}

Table 2. The information list of the cost, the resource, the quality management and the risk management of Basement $A$ 


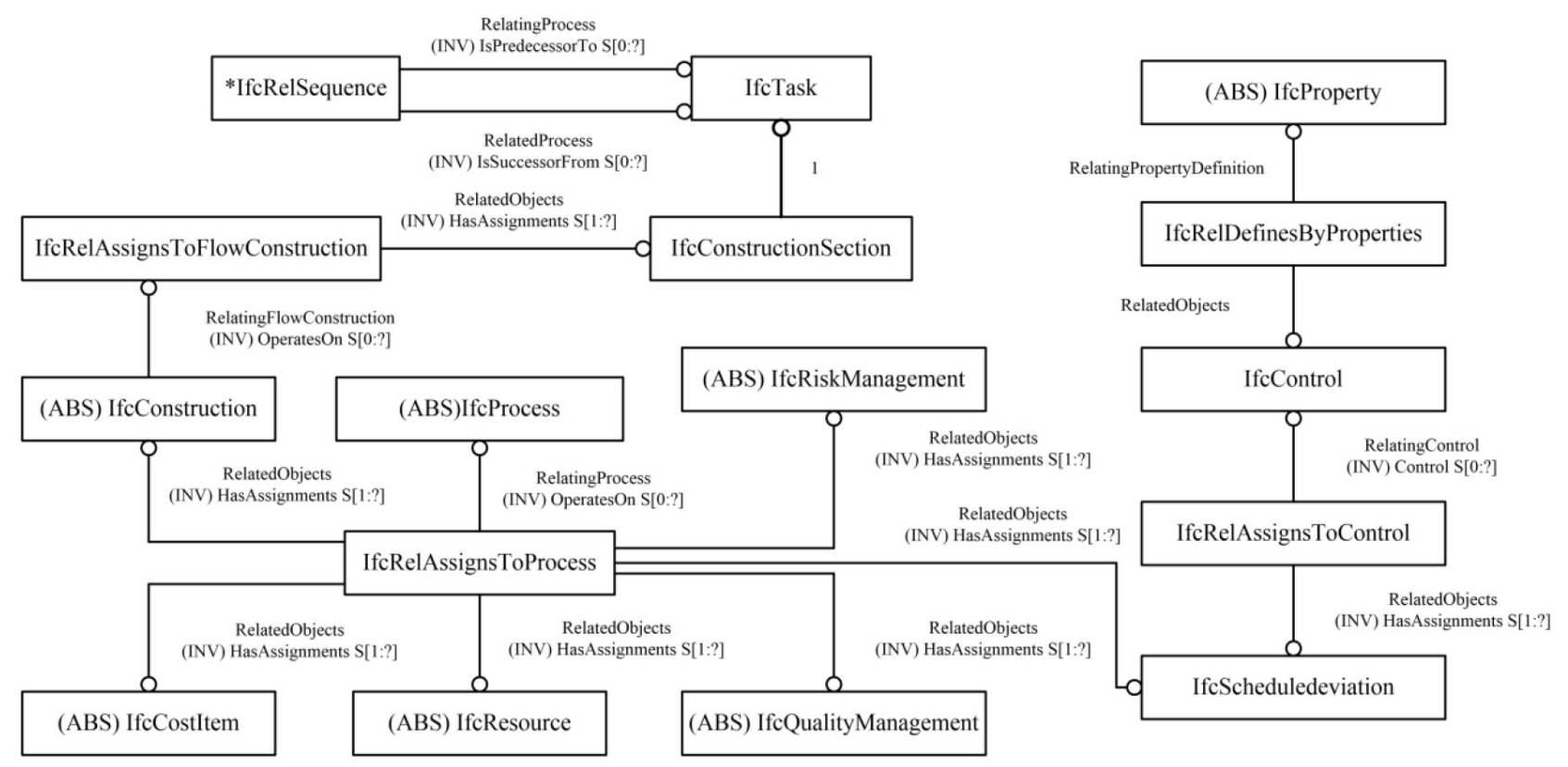

Figure 11. The schedule management information model of Basement $A$

\section{Conclusion}

The schedule management is an essential process in the construction project. Based on the construction project management theory and IDEFO, the information flow has been showed between the schedule plan, implementing, examination and control activities from the system perspective. In order to meet the information requirements for the schedule management, the new entities was extended and discussed based on the IFC4, and different information models of the schedule management are established respectively. In the integrated schedule management information model, the logical relationships among the schedule plan, implementing, examination and control are realized. Through setting the properties, the activities can be described better by the IFC standard.

The integrated schedule management information model is established, but the deeper research should be done in the future: (1) it is necessary to improve the IFC standard for the cost, the resource, the quality management and the risk management; (2) the relevancies among the cost, the resource, the quality management, the risk management and the schedule should be researched deeper to describe the dynamic and complex construction process as a whole; (3) the more detailed information model can be established; (4) based on the information models, the application software should be developed to meet the requirements of the construction project and improve the productivity. 


\section{Acknowledgement}

This study is supported by the National Natural Science Foundation of China (NSFC) (Grant No. 51378160 and 71201038$)$.

\section{References}

BuildingSMART (2014). Industry foundation classes. Retrieved March 22. http://www.buildingsmart-tech.org

Dave, B., \& Koskela, L. (2009). Collaborative knowledge management - a construction case study. Automation in Construction, 18(7), 894-902. http://dx.doi.org/10.1016/j.autcon.2009.03.015

El-Diraby, T.A., Lima, C., \& Feis, B. (2005). Domain taxonomy for construction concepts: toward a formal ontology for construction knowledge. Journal of Computing in Civil Engineering, 19(4), 394-406. http://dx.doi.org/10.1061/(ASCE)0887-3801(2005)19:4(394)

Erdogan, B., Anumba, C.J., Bouchlaghem, D., \& Nielsen, Y. (2008). Collaboration environments for construction: implementation case studies. Journal of Management in Engineering, 24(4), 234-244. http://dx.doi.org/10.1061/(ASCE)0742-597X(2008)24:4(234)

Faraj, I., Alshawi, M., Aouad, G., Child, T., \& Underwood, J. (2000). An industry foundation classes web-based collaborative construction computer environment: WISPER. Automation in Construction, 10(1), 79-99. http://dx.doi.org/10.1016/S0926-5805(99)00038-2

Froese, T.M., \& Yu, K.Q. (1999). Industry Foundation Class Modeling for Estimating and Scheduling. Proceedings of 8th International Conference on Durability of Building Materials and Components. Vancouver (Canada). 30 May - 03 Jun.

Fu, C., Aouad G., Lee, A., Mashall-Ponting, A., \& Wu, S. (2006). IFC model viewer to support and model application. Automation in Construction, 15(2), 178-185.

http://dx.doi.org/10.1016/j.autcon.2005.04.002

Göekce, K.U., Göekce, H.U., \& Katranuschkov, P. (2013). IFC-based product catalog formalization for software interoperability in the construction management domain. Journal of Computing in Civil Engineering, 27(1), 36-50. http://dx.doi.org/10.1061/(ASCE)CP.1943-5487.0000194

Hammad, A., Wang, H., \& Mudur, S.P. (2009). Distributed augmented reality for visualizing collaborative construction tasks. Journal of Computing in Civil Engineering, 23(6), 418-427. http://dx.doi.org/10.1061/(ASCE)0887-3801(2009)23:6(418) 
He, Q.H., Luo, L., \& Ren, J.S. (2012). Comprehensive optimization path of project complexity: an empirical study of the world expo $A B$ area project. Journal of Engineering Management, 25(6), 653-659.

Isikdag, U., \& Underwood, J. (2010). Two design patterns for facilitating building information model-based synchronous collaboration. Automation in Construction, 19(5), 544-553. http://dx.doi.org/10.1016/j.autcon.2009.11.006

Lorterapong, P., \& Ussavadilokrit, M. (2012). Construction scheduling using the constraint satisfaction problem method. Journal of Construction Engineering and Management, 139(4), 414-422. http://dx.doi.org/10.1061/(ASCE)CO.1943-7862.0000582

Ma, Z., Wei Z., \& Zhang, X. (2013). Semi-automatic and specification-compliant cost estimation for tendering of building projects based on IFC data of design model. Automation in Construction, 30, 126-135. http://dx.doi.org/10.1016/j.autcon.2012.11.020

Ma, Z.L., Wei, Z.H., Song, W., \& Lou, Z. (2011). Application and extension of the IFC standard in construction cost estimating for tendering in China. Automation in Construction, 20(2SI), 196-204. http://dx.doi.org/10.1016/j.autcon.2010.09.017

Man, Q. P., \& Sun, C. S. (2011). Construction information model based on IFC. China Civil Engineering Journal, 1, 239-243.

Nepal, M.P., Zhang, J., Webster, A., Staub-French, S., Pottinger, R., \& Lawrence, M. (2009). Querying IFC-based building information models to support construction management functions. Proceedings of the 2009 Construction Research Congress: Building a Sustainable Future. Seattle (USA). 5-7 April.

Nikas, A., Poulymenakou, A., \& Kriaris, P. (2007). Investigating antecedents and drivers affecting the adoption of collaboration technologies in the construction industry. Automation in construction, 16(5), 632-641. http://dx.doi.org/10.1016/j.autcon.2006.10.003

Singh, V., Gu, N., \& Wang, X. (2011). A theoretical framework of a BIM-based multi-disciplinary collaboration platform. Automation in Construction, 20(2), 134-144. http://dx.doi.org/10.1016/j.autcon.2010.09.011

Soibelman, L., Sacks, R., Akinci, B., Dikmen, I., Birgonul, M.T., \& Eybpoosh, M. (2010). Preparing civil engineers for international collaboration in construction management. Journal of Professional Issues in Engineering Education \& Practice, 137(3), 141-150. http://dx.doi.org/10.1061/(ASCE)EI.1943-5541.0000044

Tanyer, A. M., \& Aouad, G. (2005). Moving beyond the fourth dimension with an IFC-based single project database. Automation in Construction, 14(1), 15-32. 
Tse, K. T., Wong, A. K., \& Wong, F. K. (2005). Modeling objects and interfaces in building information modeling. Proceedings of International Conference on Computing in Civil Engineering. Cancun (Mexico). 12-15 July.

Vanlande, R., Nicolle, C., \& Cruz, C. (2008). IFC and building lifecycle management. Automation in Construction, 18(1), 70-78. http://dx.doi.org/10.1016/j.autcon.2008.05.001

Weise, M., Liebich, T., \& Wix, J. (2009). Integrating use case definitions for IFC developments. Ework and Ebusiness in Architecture and Construction. Proceedings of 7th European Conference on Product and Process Modeling. Sophia Antipolis (France). 10-12 September.

Zhang, J.P., Yu, F.Q., Li D., \& Hu, Z.Z. (2014). Development and implementation of an industry foundation classes-based graphic information model for virtual construction. Computer-aided Civil and Infrastructure Engineering, 29(1SI), 60-74. http://dx.doi.org/10.1111/j.14678667.2012.00800.x 


\section{Appendix A}

\begin{tabular}{|c|c|}
\hline No. & Name of the Property Set \\
\hline 1 & The construction contract \\
\hline 2 & The construction budget \\
\hline 3 & Engineering quantity \\
\hline 4 & The amount of labor \\
\hline 5 & The schedule report \\
\hline 6 & The amount of machinery one-shift \\
\hline 7 & Statement of the construction \\
\hline 8 & Completion report of construction work \\
\hline 9 & Quality objective \\
\hline 10 & The quality check of material approach \\
\hline 11 & The reject management \\
\hline 12 & Precaution \\
\hline 13 & Quality assessment of the unit project \\
\hline 14 & Quality assessment for working procedure of the reinforcement \\
\hline 15 & Quality assessment for working procedure of concrete pouring \\
\hline 16 & The cost plan for the safe construction \\
\hline 17 & Emergency preparedness and response \\
\hline 18 & Contract management \\
\hline 19 & Materials management \\
\hline 20 & Mechanical cost management \\
\hline 21 & Labor cost management \\
\hline 22 & Other costs \\
\hline 23 & Cost accounting \\
\hline 24 & Records of the technological explanation \\
\hline 25 & Risk factor \\
\hline
\end{tabular}

Property sets required in the examination and control information model

Article's contents are provided on a Attribution-Non Commercial 3.0 Creative commons license. Readers are allowed to copy, distribute and communicate article's contents, provided the author's and Journal of Industrial Engineering and Management's names are included. It must not be used for commercial purposes. To see the complete license contents, please visit http://creativecommons.org/licenses/by-nc/3.0/. 